\title{
How to face "design thinking": Human-centered problem solving and designer's attitude to approach
}

Takehiko Yogo

GK Dynamics Incorporated

Follow this and additional works at: https://digitalcommons.uri.edu/mgdr

Part of the Art and Design Commons, and the Business Commons

\section{Recommended Citation}

Yogo, Takehiko (2019) "How to face "design thinking": Human-centered problem solving and designer's attitude to approach," Markets, Globalization \& Development Review. Vol. 4: No. 2, Article 5.

DOI: 10.23860/MGDR-2019-04-02-05

Available at: https://digitalcommons.uri.edu/mgdr/vol4/iss2/5

This Dialogue is brought to you for free and open access by DigitalCommons@URI. It has been accepted for inclusion in Markets, Globalization \& Development Review by an authorized editor of DigitalCommons@URI. For more information, please contact digitalcommons-group@uri.edu. 
How to face "design thinking": Human-centered problem solving and designer's attitude to approach

\section{Markets, Globalization \& Development Review}
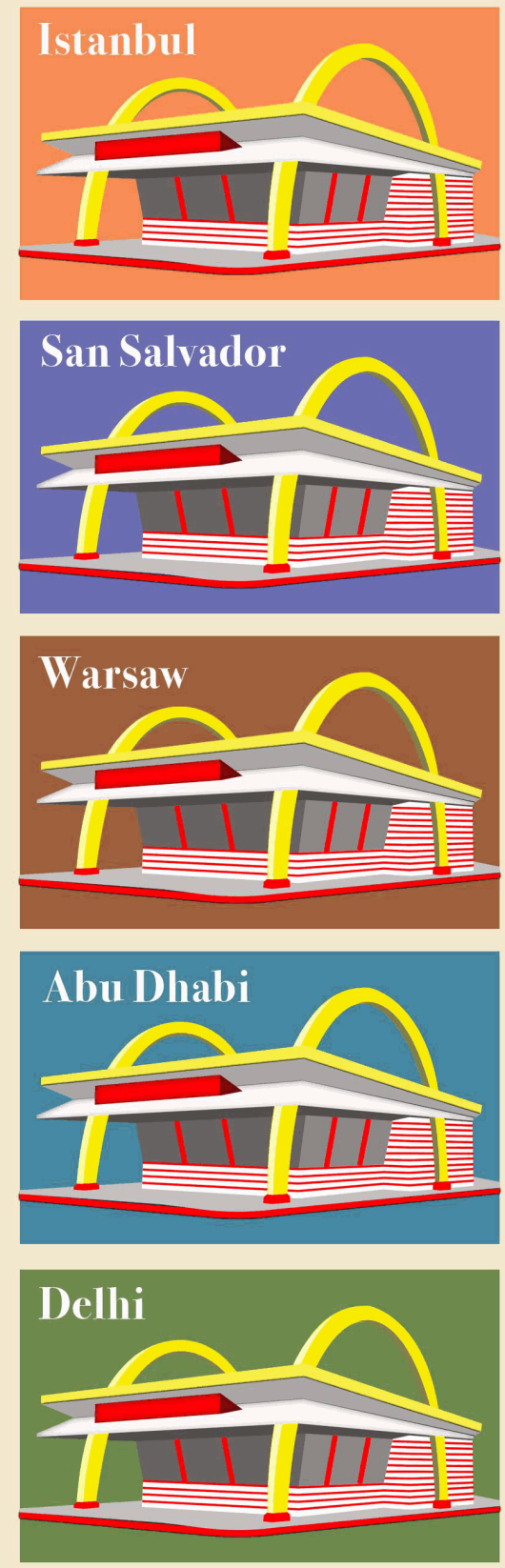
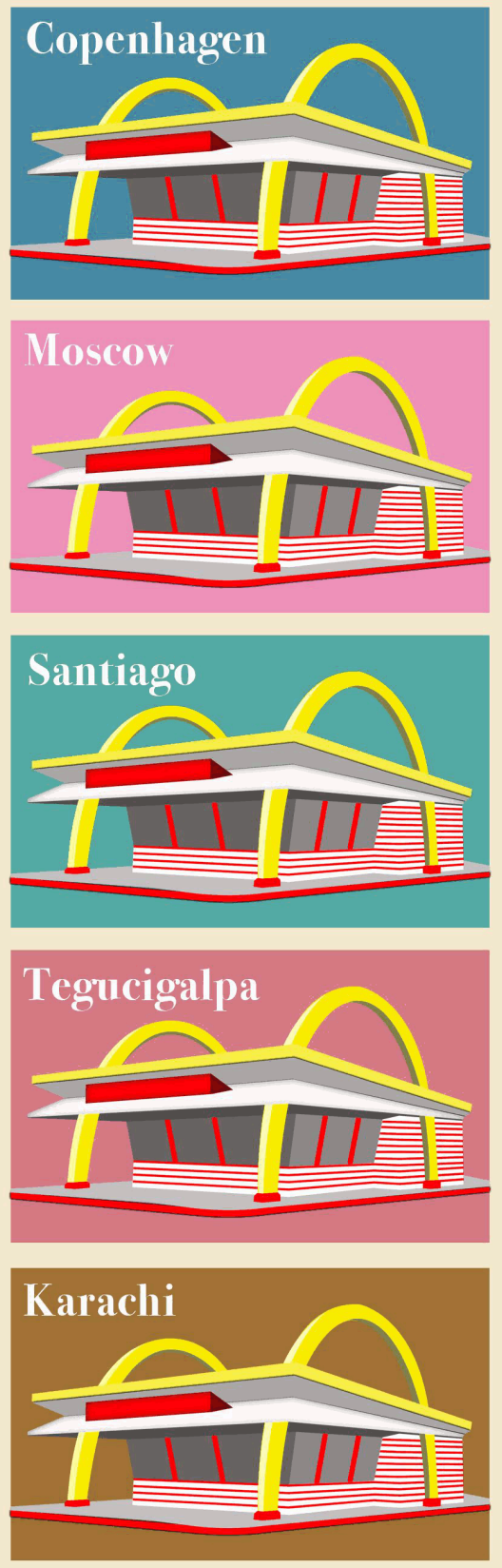
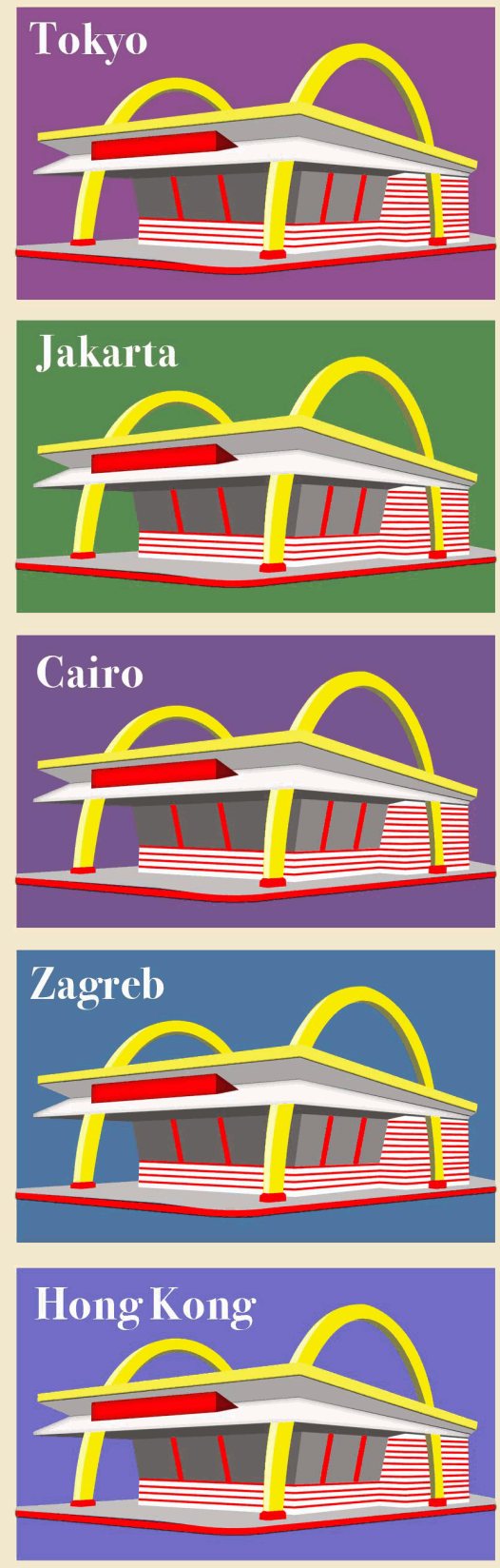

This dialogue is available in Markets, Globalization \& Development Review: https://digitalcommons.uri.edu/mgdr/ vol4/iss $2 / 5$ 


\section{How to Face "Design Thinking": Human- Centered Problem Solving and Designer's Attitude to Approach}

\section{Introduction}

The author is a member of GK Dynamics which is part of the GK Design Group. The history of GK Design Group started with that the late Kenji Ekuan, Chairman of GK Design Group formed a "GK Industrial Design Room" with a slogan "Democratization of beauty" and "Democratization of goods" with his colleagues in 1952, while studying at Tokyo University of the Arts. Mr. Ekuan witnessed his hometown of Hiroshima burned to the ground and everything destroyed after World War II. He strongly hoped for a society in which the people who lost everything were able to enjoy a comfortable life and the richness of their hearts equally. People can raise their convenience in life by getting what they need and they can feel "beauty." Mass-produced products with beautiful design and made available for every citizen is the "Democratization of beauty" and the "Democratization of goods" that was Mr. Ekuan's aim for industrial design. He established "GK Industrial Design Institute" in 1957, and they have created an unprecedented new trend that design specialists group received orders of product design that have been held within the company until then. $\mathrm{He}$ was a pioneer who explained and disseminated the importance of design early in postwar Japan when even the word "design" was not recognized, and his influence spread to the world. The masterpieces of Mr. Ekuan are left everywhere as achievements that supported modernization of Japanese lives and the urban spaces. In addition, he struggled to create an organization to open up the function of design to the society and the research to delve deeper into what people and design should be (Ekuan 1997; Fujimoto and GK History Compilation committee 2002; NPO PLAT 2016; Sakai et al. 2013). Currently the GK Design Group consists of 12 companies in total, including 8 companies in Japan and 4 overseas companies, GK covers a wide range of disciplines including: Product design, Mobility design, Environmental design, and Communication design. We are a design creation group featuring design engineering and design strategy as well as providing consistent design, research, planning development, information provision for software and hardware production.

The Kikkoman soy sauce tabletop bottle released in 1961 is the design that GK worked on. Until then, in Japanese homes, they purchased 
soy sauce in a large container, then the soy sauce was poured into a smaller serving vessel and placed on the table for each day use. Purchasing in a large bottle was difficult to carry and time consuming to parcel out, moreover the spilled soy sauce could easily soil the kitchen. GK designed a soy sauce bottle of table-top size that could be used just as it was purchased. It has an exquisitely angle-adjusted spout to prevent careless droplets, and a form created in consideration to the ease of holding and pouring. It has a dignified appearance to add a beautiful accent to Japanese dining tables. The bottle raised the convenience in purchasing, cooking and gave richness to Japanese table scenes. Now with the spread of soy sauce abroad, the design of this bottle has been shipped all over the world and has become an icon of the company enjoying a long sales life (GK History Compilation committee of GK Design Group 2002). This tabletop bottle brought innovation as not large-scale transformation with cutting-edge technology, but from just one scene of very common daily lives. It says the innovation can produce changes that serve people and society regardless of the magnitude and process of the scale.

Through this example of small product, we GK people has learned how to take important viewpoints to improve the future society with values and lifestyles being complicated, namely how to take an attitude to understand consumers and solve the problems using abilities of flexible ideation and realization.

Figure 1: Soy Sauce Tabletop Bottle (Kikkoman Corporation, 1961)

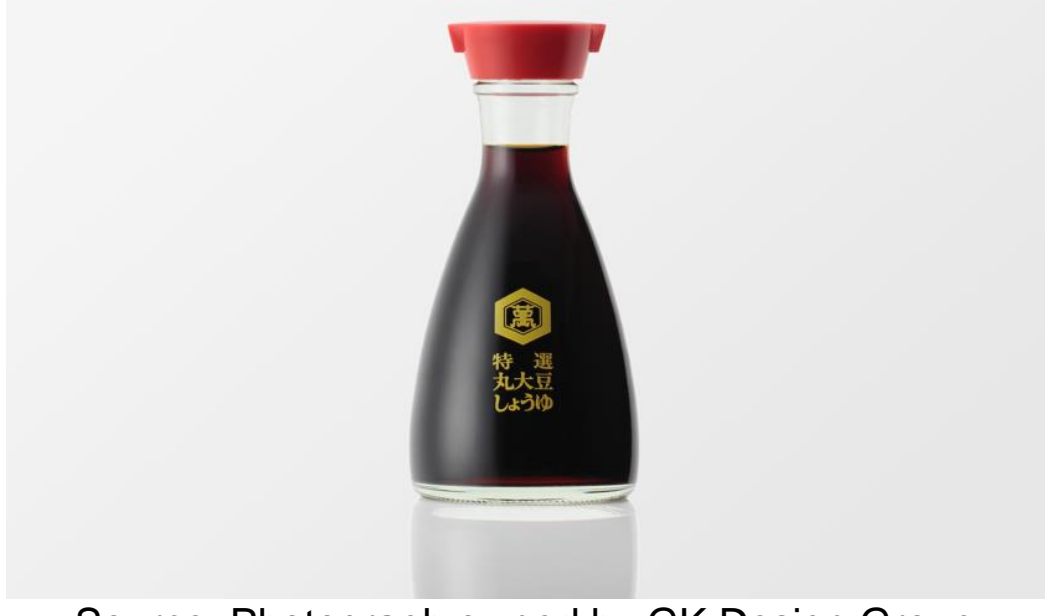

Source: Photograph owned by GK Design Group 


\section{About GK Dynamics}

Among the group; GK Dynamics has long been engaged in the design of mobility centered on personal vehicles. We have had an extensive relationship with Yamaha Motor Co., Ltd., since their founding in 1955. We have built trusted relationships for over half a century through the designing of various vehicles, including motorcycles. GK Dynamics has engaged in such mobility design, does not have a department specialized in "design thinking" at the center of their business, and there is not a large number of professional "design thinkers" employed there. The members involved in the work are composed mainly of "designers to make things" such as product and graphic systems. However, the term "design thinking" has been part of the design lexicon for some time, and the way people understand the work of design has also transformed from the conventional ideas. There has been a "shift from things to experiences," this new value has been spreading in general and it has had a large influence on our work.

The author was involved in graphic design work at GK Dynamics; and after working on many projects in Japan and our offices abroad, he was selected to work as design management. Through that experience, though he acknowledges the effectiveness of "design thinking" for problems that are difficult to deal with by conventional processes only, he considers that it is necessary to be careful about how to use them. he would like to consider how GK Dynamics is facing the trend toward "Design Thinking" and how we should utilize it for our work.

\section{How to understand General "Design Thinking"}

First of all, how "design thinking" is understood will be examined. "Design Thinking" has been the point of discussion through a variety of media since architect Peter G. Rowe used the word "Design Thinking" for the title of his book published in 1987, and had been also mentioned by John E. Arnold (1959/2016) and L. Bruce Archer (1965) et al. Many ideas on the subject have been put forth, but in general "Design Thinking" is a way of solving problems in business or society by using the concepts and methods common to design.

In other words, it is the method of applying a series of processes such as Intuitive hypothesis formation, Concept creation, and Prototype verification techniques that designers have used in design work to find problems and solutions. This means design which was considered as a specialty area of thinking used only by designers, has been recognized as "knowledge" and that all people can utilize these ideas to solve diverse problems (Konno 2010; Brown 2010). 


\section{Why is "Design Thinking" Gazing?}

So why has "Design Thinking" become such a phenomenon? Reason is that increasingly complicated today, it is no longer easy for many companies and organizations to create innovation, and the trend to make use of "Design Thinking" to break down the situation has intensified. The factors considered from a designer's point of view are described below.

\section{Shift from Things to Experiences}

The first factor is that the world overflows and businesses can no longer thrive on simply making good products. The time when the value of a product was improved by incorporating new function has come to an end. consumers are now focused and aware on what is really necessary for their own life. As a result, they demand the value not only in the superiority of a product's function, but also in how to use it, how to purchase it and how it benefits their life. Thus, the innovation has become increasingly difficult with conventional processes. The circumstances are demanding a change in value that people recognize as "a shift from things to experiences."

\section{Projects Shift to Participate Type / Co-creation Type}

The second factor is that various kinds of information sharing have expanded, and many stakeholders now participate to produce the final outcome. Formerly in Japan, municipal public works had been carried out in a top-down management style based on a simple structure only between the government as the orderer and the company as the contractor. However, as increasing awareness of issues throughout society regarding the fairness of business ordering and the impact on living environment, the understanding formation and project progress with the private sector became important. "Design Thinking" came to be used to bring a better solution, while utilizing a large base of knowledge and building consensus timely. As a result, it became important to listen and use the opinions of users of products and services who had been the consumers in the past, and they also had the opportunity to participate as creators.

\section{"Democratization" of Design}

"Democratization of design" as another major factor means that both interest/knowledge and execution/ability of design become generalized widely. In the past the product was "given" from the producer side. Design was regarded as a specialized field which is carried out by making full use of the designer's special sensibility, ideation ability and their skill of creation. However, with the progress of informatization on a global scale, the various design cases and the thinking way to produce them had been widely known to the general people other than designers. And then Adobe the maker of 
creative software issued the message at "Adobe Symposium 2018 (2018 Sep. 4-5, Tokyo)" that they realized "democratization of professional skills", and "providing creativity as a service" could be achieved by utilizing their AI "Adobe Sensei". The development of various digital tools in recent years has made it possible to synchronize the most advanced information in every part of the world; and it's changing creative activities to what many people can do, not just the designer's privilege. In this way, design has become a more familiar presence for people, and their recognition is changing to what is considered by everyone and produced by themselves participating in it, that has promoted open innovation and user innovation to spread in the present.

\section{History of "Design Thinking" in GK Dynamics}

GK Dynamics has been engaged in the activities leading to "Design Thinking" through our product design work. Especially we have had a lot of projects for Yamaha Motor Co., Ltd., which has long been a major client. Here the progression of our working on those subjects will be looked back on.

\section{Observation through CMFG}

GK Dynamics calls the key elements of our graphic design work as "CMFG" (Color/Material/Finish/Graphic). CMFG does not directly contribute to improving the function and performance of the motorcycle in terms of speed and power. However, it's easy to imagine that in a state where only the fundamental parts necessary to derive pure performance were combined; even if the price was inexpensive, the users would not feel a willingness to own the vehicle. The point to owning the vehicle would be unclear, because it could not be clearly imagined how this machine would fit in the users' life, even though its function could be understood. The objective of creating a design model is relatively clear; it allows the designer to check the form and determine if it meets requirements such as product function, operational performance and visual appeal. On the other hand, it's not easy to find out why a color or graphic pattern is "correct." Sometimes the task to only change the coloring of a vehicle without any other functional improvement should be taken. Often the direction to express strength or speed feeling, elegance, mechanical sophistication, adoption of a trend color, or emphasizing the brand's own color history will be gotten. With these overflowing choices, clarification is needed as to what kind of character should be expressed.

Therefore, in order to find the reason for the CMFG thorough understanding the user must be needed. Our ability to create ideation and 
context formations are necessary. it must be considered how the product exists in the market and its background, how it will be valued in the future and its relationship with surrounding competitor products. In other words; "meaning" must be given to the existence of an individual product while also providing its "relationship" with the surroundings, that is the important role of CMFG.

\section{Prototyping of Experience Type Survey}

In motorcycle design work, research activities have been also focused in cooperation with our client. Various surveys have been conducted for more than 20 years in the Southeast Asian market. Generally, one of the characteristic points of motorcycles is people want the taste of hobby and the variety of uses on it. In Asian markets including Southeast Asia, the number of colors available for motorcycles tends to be larger than in other developed markets like the Occident. With the large market there, variations of colors and graphics that suit the needs of many users with different purposes of use had been required.

Our research methods such as focus group interviews with customers sensitive to trends by using specific idea sketches of product, grasping their actual lifestyle by visiting the user's home and creating a dialogue with the local community are not special compared to commonly known methods. What GK Dynamics emphasizes the most is that the designers themselves investigate the customer with a hypothesis, then observe the actual market and user; and create a break through idea based on a hypothesis verification. To make each year research more effective we depend on the quality of the primary information obtained by the designer's own experience. By sharing information of our experiences obtained over the years, our team members gradually inherit the knowledge and understanding of the market and the users. Our knowledge gets deeper and our sense of how to find problems and solutions becomes a multi-viewpoint exercise. It then functions as a system to find new discoveries. At the dawn of research activity, most testing was in the form of 'like or dislike-type questions', but gradually the answers were put into context "verified by our hypothesis proposal" and the studies became stronger. As the designer's own experience increased, they were able to notice the market and user needs change as well as the intangible/emotional needs. The research activities themselves became a form of "prototyping for future proposals".

It's an important point common to "Design Thinking"; whether thinking about how to interpret "meaning and relationship" and linking "prototype" with repetition to the solution of problems. It can be said that the accumulation of these tasks has become a strong base to deepen our "Design Thinking". 


\section{Feature of Approach to Motorcycle Design by GK Dynamics}

As described above, in the design development process, we have enhanced contact with users and have conducted various analysis and hypothesis verification, but we have not taken the style of co-creation with actual users basically. It largely depends on the characteristics of the target of design. That is, in the case of products that needs taste of hobby like motorcycles, "improvement" that eliminates the problems users perceived is not effective, but "providing new value" beyond users' imagination is needed. Then it is difficult to make right advances through the co-creation that emphasizes users' own opinions.

The spreading of awareness increase of design among people in general society becomes the basis for enhancing design quality with "Democratization of design" mentioned above, however even high creativity, ability of expression, problem solving and realization are not necessarily generalized as the development and spread of creative tools. Designer should appreciate that users don't talk about every solution and find their mind out and make good proposal for them.

\section{Examples of Practical Application of "Design Thinking"}

Through the circumstances described above, there have also been changes in how GK Dynamics approaches the business of design though our process originally based the design work on the product itself. Some examples will be introduced here.

\section{Example-1: A Sport-Related Work}

Problem Finding and Ingenuity of Approach to Users

Initially, our work started by focusing on individual product designs ordered by the client. However, as our work continued forward, it became clear that a major point was not being successfully conveyed, even though there was a functional advantage beyond the competitors. We were able to convince the client that it's important not to merely create individual products, but to build a connection, making the product more attractive to its users. We also shared the awareness of this problem among each other, in order to provide better products to users. As a result, the work applied not only to the design of the product itself, but to develop a promotion plan to properly connect the product and the users also. Then it is about to begin to improve a series of processes from planning to manufacturing and sales. 


\section{Example-2: A Mobility-Related Work}

Solution Proposal not based on Physical Design

When integrating IT devices in mobile products, it can be difficult to make a large impact on appearance from the basic model. What we sought in this project was not to look at the appearance of the product itself or software development, but to show the idea of naming to make the products attractive to users. Because the main target was the North American market, we cooperated with GK Design International, the GK Group's North American base. We investigated how the naming in North America could be established and the image that the name gave to the user, and we presented the way the customer would feel based on the naming.

\section{Example-3: A Mobility-Related Work}

\section{Workshop to Make Co-creation with Clients}

Just working on the shaping of form can no longer improve the quality of product design to be competitive. It is important to grasp how the users' experiential values are created through that product. Therefor we created tools and workshops to deepen and share understanding of a series of experiential value formation among project stakeholders. A system based on tracing experience when the user is in contact with the product, and by making unique "ways to words" explanations were used for evaluation, this technique raised the awareness of workshop participants and we received more than merely a good or bad judgment for their own products, but the result of enriching the studies direction and the design creation afterwards. Through these activities, we moved to a new co-creation stage with the design team of client.

\section{Example-4: A Physical Equipment for Treatment}

\section{Search for the Optimum Solution for Users}

In promoting the design of a medical device which supports the lower leg of stroke victims, we found through observation and dialogue with users that the importance to them was not "treatment" but "a happier life". We aimed to give them a feeling of walking on their own, they did not mind if they were seen wearing such equipment in their daily life. Our design featured a minimal metal frame structure that could be concealed under clothing and allowed easy fitting. The devices appearance was like lightweight sports gear and gave a pleasant feel to use contributing to a positive attitude of the users. Although such devices are generally produced in different sizes to fit different size people, it is also a great advantage for users to have a structure that can accommodate a wide range of adjustability. Searching for 
an optimal solution that is integrated with such engineering is also an important element in "Design Thinking" (Mitomi 2018).

Figure 2: Gaitsolution Design (Kawamura Gishi Co., Ltd., 2005)

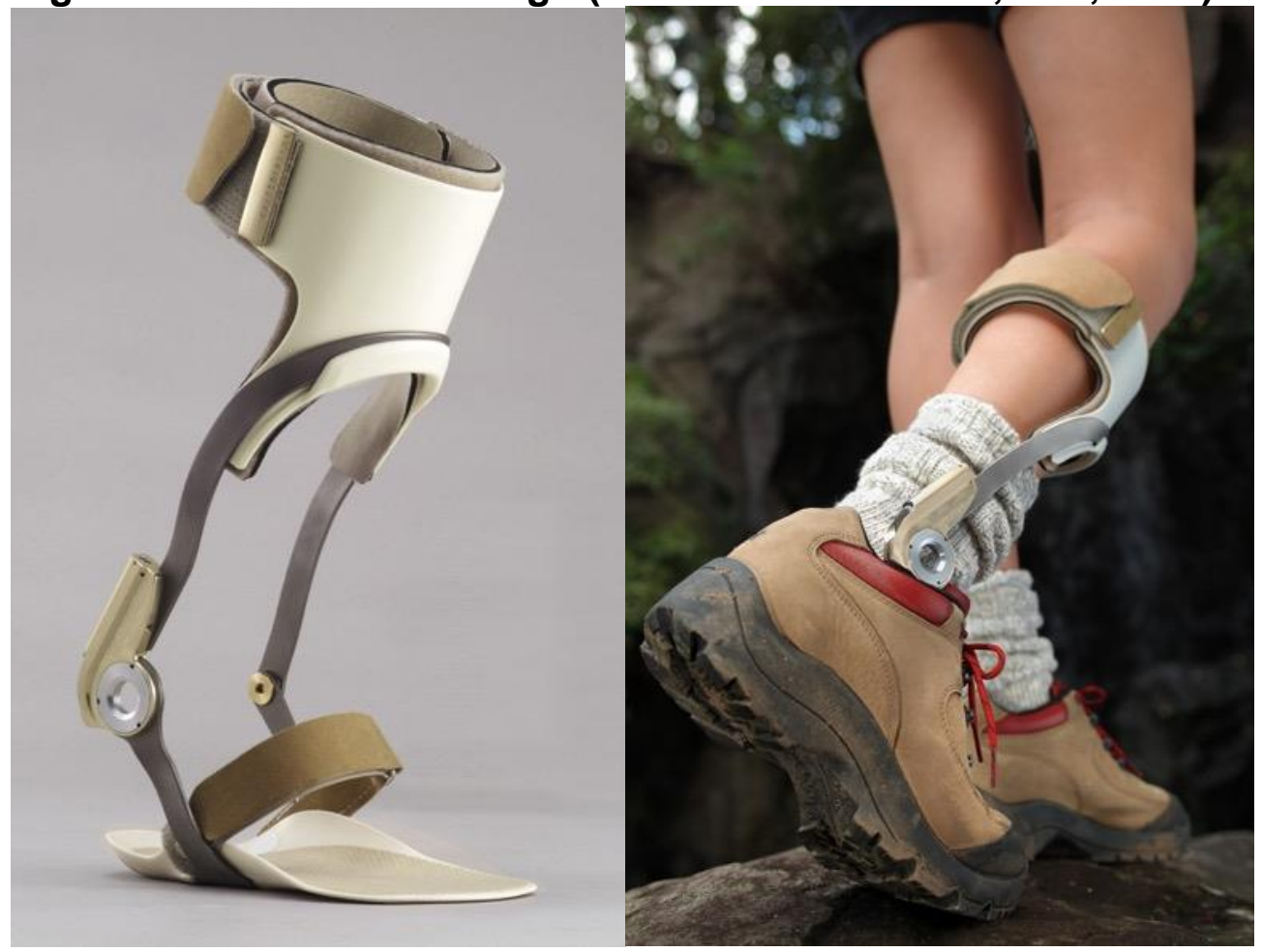

Source: Photograph owned by GK Design Group

\section{What is "Design Thinking" Aiming for?}

Now the word "Design Thinking" is becoming more general in business and it is natural to adopt it in promoting a project. However, "Design Thinking" itself is not a universal equation for problem solving. According to Tomoko Kawakami (2015), professor of Waseda University, customer-oriented thinking is effective for improving product, but it tends not to be effective for innovative new product development. There is no doubt that it is important to listen to not only the manufacturer of products and services, but also to users and to make use of it in providing experience value. However, the point to keep in mind is that even if the experiential value is ultimately gotten through the experience of the users, not all products and services themselves that provide experiential value can be produced by users. Similarly, it is important to take the opinions of each related division and deepen common understanding by repeating trial and error. Merely adopting the process of "Design Thinking" in a stereotype manner can raise 
the awareness of project participants, but there is a risk that the final result will become typified and ordinary.

GK Dynamics traditionally sticks to "making design." We constantly focus on improving the quality of form and continue to study the final product. On the other hand, we also place importance on improving capabilities that are not bound by conventional business styles. The ability to "think about intangible matters and give answers on tangible things" will become more relevant within society. In recent years, it is likely that many people have misunderstood the importance of both the experience and the product, because their focus has primarily been on just the importance of experience. However, originally both "things and experiences" are important. Existing things that are actually touchable, visible, and usable provide a realistic experience. "thing" plays the role as an important memory device of experience.

In order to derive a balanced solution focusing on such "things and experiences", the first thing we should do as a designer is making project personnel repeat "thinking" and "making," and prepare "places" where they can deal with repeated measures and reach specific goals. This is not only a physical space but also an atmosphere creation and progress adjustment. This will encourage the exchange of opinions for those who are involved (see Figure 3). Another important thing is providing "contents" to activate the "place" as well. There is a possibility to widen the doors to many participants but also to show the power of concrete suggestion. This is enough to guide the whole to reach an optimum solution which eventually has a big influence on the success or failure of the project (see Figure 4). In that matter, it must be not forgotten to figure out whether the proposal is truly beneficial for people (see Figure 5). In other words, it is important to participate in finding problems as a "design thinker," present solutions as "practical designers," and consider benefits as "users" in a timely manner.

Figure 3: Making Project as Repeat "Thinking" and "Making," and Prepare "Places"

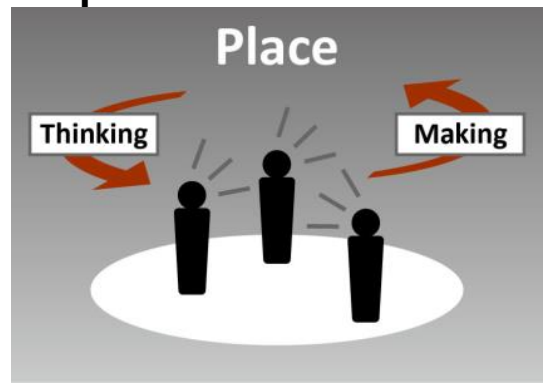


Figure 4: Providing "Contents" to activate the "Place" as well.

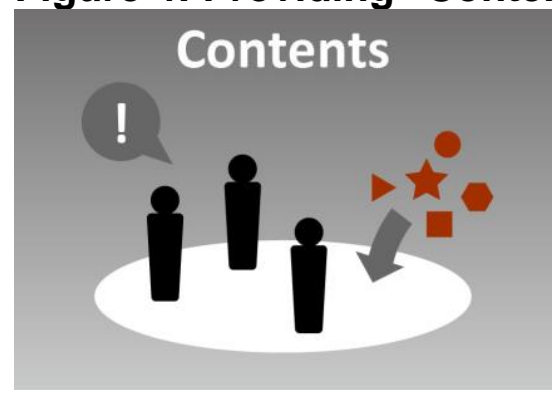

Figure 5: Figuring out whether the Proposal is truly Beneficial via "Users' View"

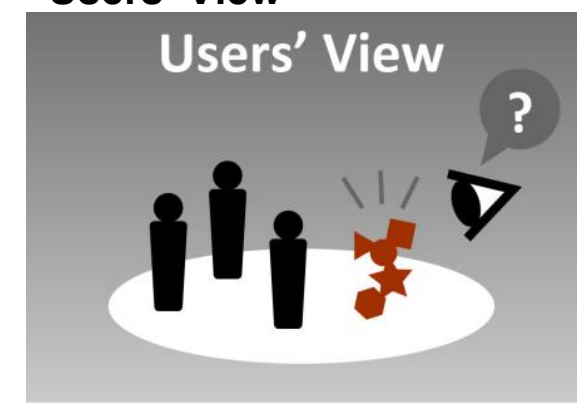

Source: Author's conceptualization (Figure 3-5)

In the case of GK Dynamics, through the experiences involved in long-term design mainly within personal mobility, we have deepened the understanding of the relationship between "joy and pleasure" sensed by humans and "manipulating tools using the body". The important point of "Design thinking" aimed at GK Dynamics is to make use of it in various solutions through both "things" and "experiences," by imagining how "joy and pleasure," physical or mental, builds up the experiential value. As keywords such as CASE (Connected / Autonomous / Shared / Electric) and MaaS (Mobility as a Service) are drawing attention, the mobility business is in the midst of the fierce flow as changing today. The case as not "Beneficiary=Driver=Owner" but as "Beneficiary=Non-Driver=Non-Owner" must be increasing. In the future, it's getting important to take measures to not only "Design for vehicle itself" but also "Surrounding environment and services" and "User \& non-user lifestyle". Then working with various companies and creative teams as different from usual should be needed. At that time, how we can take a flexible approach with the above three stances that designer should take. 


\section{Conclusion}

When visiting a bookstore recently, it is surprising a lot of number of knowhow books are found. Some were related to the concrete techniques of design, and many were related to "Design Thinking." It seems that many people are trying to find a more effective way to design things. The word "Design Thinking" has penetrated society, and its effectiveness has brought about positive and negative opinions. As mentioned above, excellent project results will be never achieved if it will be used as conventional way. We must not be satisfied with only incorporating a process like open innovation or user innovation that are recommended in reference books for "design thinking". Certainly, "Design Thinking" is a convenient method for problem solving, however it should not be accepted in a standardized form, it should have flexibility. Even though the idea of "human-centered" is fundamental, how the viewpoint is set and to what kind of people is necessary to be flexible and deliberate to the challenges faced. And also, we must understand that "design thinking" is a way of thinking to approach good things and services, but it doesn't achieve the abilities of expression and realization needed finally. A thought of "Design is becoming too important of a matter to leave it to designers alone," as T. Brown talks in his own book has been established in society. But it can be grasped that it does not deny the ability and possibilities of the designer. The ability to cope with complicated cases and the ideation and realization based on esthetics is an important ability that designers should show on their own initiative.

In the near future many types of job will be separated from people. In design, variety and response speed of ideation is no match for Al. In such era as technology will continue to develop further and release people from many troublesome jobs, the author thinks that the thinking stance of us human being who is responsible for "Design Thinking" to come up with a human centered solution become more important. That is, it is even more important to think about measures by accurate detecting people's mind, pain or joy, and for that purpose, not only the results derived automatically from the analysis of a large amount of data in the past, but also imagination as human being becomes essential. It is only now that the solution process as "Design Thinking" has been known widely, and whole society has recognized the importance and benefits of design, determining again the essence as "what to do" for various problems with human's own imagination is getting significant. At that situation, designers should be required to have the ability to engage in overall stages as "Discovering issues that are often overlooked in general", "Sharing issues and making cooperative relationships with others", and "Presenting specific solutions", but not just one of them. 


\section{References}

Archer Bruce L. (1965), Systematic Method for Designers, Great Britain: Council of Industrial Design.

Arnold, John E. (1959/2016), Creative Engineering. In W. J. Clancey (Ed.), Creative Engineering: Promoting Innovation by Thinking Differently, (Original manuscript 1959), Stanford Digital Repository, (accessed on March 3, 2019), [available at: http://purl.stanford.edu/jb100vs5745].

Brown Tim (2010), CHANGE BY DESIGN How Design Thinking Transforms Organizations and Inspires Innovation, Tokyo: Hayakawa Shinsho, 16.

Fujimoto Kiyoharu and GK History Compilation Committee (2002), GK Monogatari -The Story of GK Since 1952, Tokyo: GK Design Group Incorporated, 8-10, 132-35.

GK History Compilation Committee of GK Design Group (2002), GK Design 50years 1952-2002 Design World Exploration, Tokyo: Rikuyosha.

Kawakami Tomoko (2015), "Three Reasons why Co-creation Community is Prone to Failure - Whether the Age of Co-creation will Come, \#2", (accessed on March 1, 2019), [available at http://www.dhbr.net/articles/-/3229].

Kenji Ekuan (1997), Kokoro Series: Hitoto Kokoroto Monono Sekai (The World of People's Minds and Things) -From Table Bottle of Soy Sause to Akita Bullet Train "Komachi", Tokyo: Horupu Publishing, 41-47.

Konno Noboru (2010), Businessnotameno Designshikou (Design Thinking for Business), Tokyo: Toyo Keizai Shinposha, 28-41.

Mitomi Takane (2018), "Fusion of Design and Engineering", GK Report, 33, 8-9.

Sakai Tadayasu et al. (2013), The Catalogue for the Exhibition for The World of Kenji Ekuan and GK Design Group: Soaring High in the Sky, Tokyo: Setagaya Art Museum, 183, 213-17. 